\title{
Interdisciplinarity as a Key Component Contributing to Sustainable Development of Modern Engineering Education
}

\author{
Elmira Raisovna Vasilyeva \\ Department of Humanities and Socio-Economic Sciences \\ Ufa State Petroleum Technological University, \\ Branch of the University in the City of Oktyabrsky \\ Oktyabrsky, Republic of Bashkortostan, Russia \\ elmira-vasilyeva@mail.ru
}

\author{
Liliya Zakarievna Samigullina \\ Department of Humanities and Socio-Economic Sciences \\ Ufa State Petroleum Technological University, \\ Branch of the University in the City of Oktyabrsky \\ Oktyabrsky, Republic of Bashkortostan, Russia
}

sliliyaz@mail.ru

\author{
Oksana Viktorovna Danilova \\ Department of Humanities and Socio-Economic Sciences \\ Ufa State Petroleum Technological University, \\ Branch of the University in the City of Oktyabrsky \\ Oktyabrsky, Republic of Bashkortostan, Russia \\ oks-danil@yandex.ru
}

\begin{abstract}
Interdisciplinarity of higher education aims to improve such interdisciplinary skills as interdisciplinary thinking. Within the scope of this study, interdisciplinary thinking is defined as the ability to integrate the knowledge of two or more disciplines, improve the learning process, and produce results that would be difficult or unlikely to achieve when using a separate discipline. It is considered as a complex cognitive skill consisting of a number of sub-skills. The review showed that to date there is a small number of scientific studies focusing on the interdisciplinary approach to teaching and learning. The study further advanced the understanding of the necessary components of interdisciplinary thinking and the typical conditions that ensure its development. This understanding will provide a basis for further development of interdisciplinarity in higher education.
\end{abstract}

Keywords - interdisciplinary thinking, interdisciplinary higher education, sub-skill, learning environment, learning process.

\section{INTRODUCTION}

Information and its role in the development of the society have increased dramatically over the past decade. In such circumstances, it is impossible to maintain the old educational system when a teacher acts as a repeater of knowledge that is rapidly becoming obsolete. Therefore, the new paradigm of education is aimed not at the acquisition of a large amount of knowledge by a student, but at the formation of the ability to obtain new knowledge independently, which corresponds to the "life-long learning" concept. At the same time, the role of fundamental and interdisciplinary knowledge increases dramatically, allowing a university graduate to be more easily oriented in related areas of professional activity and to build a non-linear model of his career development.

Compared to traditional higher education, which focuses on subject-matter knowledge and the development of general skills, interdisciplinary higher education aims to develop interdisciplinary skills. This, for example, includes the ability to change views, synthesize knowledge of different disciplines, and cope with difficulties. Unlike multidisciplinarity, which is additive, interdisciplinarity is integrative: knowledge in different disciplines is contrasted and altered through integration. The interdisciplinary nature of education allows students to choose the right educational trajectory depending on objective and subjective factors.

\section{PROBLEM STATEMENT}

The interdisciplinary approach is a major opportunity to preserve knowledge and enhance its practical relevance. Interdisciplinary links allow compressing the educational process without overloading students and teachers. Besides, interdisciplinary links allow students mastering all-cultural and professional competencies in the integrated manner. The interdisciplinary links imply that a teacher gives new material to students based on the knowledge they have gained from previous courses. This method, on the one hand, ensures better memorization of the studied material, and on the other hand, gives students an opportunity to better understand and absorb new material that will be useful for studying subjects of the subsequent courses of study. The key factors in the organization of interdisciplinary links are as follows: 1. High qualification of a teacher. He shall have full knowledge of his 
interdisciplinary thinking: "The ability to integrate knowledge and ways of thinking in two or more disciplines or in certain areas of scientific interest to create cognitive perception, such as explaining a phenomenon, solving a problem, or creating a product that would be impossible or unlikely to be accomplished through the means of individual disciplines" [4].

According to this definition, interdisciplinary thinking can be seen as a complex cognitive skill that consists of a number of sub-skills, such as the possibility of changing disciplinary concepts and creating meaningful links between disciplines. Interdisciplinary thinking does not happen spontaneously; students may take a considerable amount of time to achieve a sufficient level of preparedness in their practice. Besides, students need a teacher to help them to be able to synthesize data from two or more disciplines. Too often, curricula are called interdisciplinary, in fact being multidisciplinary: multiple concepts are presented without the ability to integrate disciplinary knowledge throughout the curriculum [5].

The difficulty of teaching and learning interdisciplinary thinking results in interdisciplinary higher education facing the challenges of producing both broad and narrow interdisciplinary thinking by students. Achieving the desired learning outcomes requires a coherent and well-designed learning environment within a coherent and student-oriented curriculum. For this reason, curricula and course developers need a comprehensive understanding of the typical conditions underlying the development of interdisciplinary thinking. This requires, for example, information on the extent to which students should have knowledge of different disciplines as well as didactic means of integration [6].

\section{RESULTS AND DISCUSSION}

Interdisciplinarity involves much more than parallel knowledge about the second or third discipline (in Russia a few years ago there was a boom that the "techies" wanted to pursue the second education in economics). It is equally important to learn to think in a way that is different from how students are used to think in their discipline. The objectives of the review were to systematically identify, critically analyze and discuss scientific research on teaching and learning interdisciplinary thinking within interdisciplinary higher education. For this purpose, the Biggs theory was used as the basis. The author proposes a comprehensive model of teaching and learning in higher education. In particular, teaching and learning are seen as a systemic interaction of four components: student, learning environment, learning process and learning outcomes [7]. This model allows curriculum and interdisciplinary education professionals gaining a comprehensive understanding of teaching and developing interdisciplinary thinking. Besides, the model is based on the principle of equality meaning that teaching and learning are combined with desired learning outcomes. This principle leads to a result-oriented approach to teaching and learning, which facilitates the development of a coherent and pedagogicallybased curriculum [8].

The main purpose of this review was to identify the subelements that serve as components of interdisciplinary thinking and typical conditions for the development of Veronica Boix understanding or interdisciplinary thinking. 
paradigm knowledge of disciplines. The acquisition of this knowledge appears to be required to enable students to go beyond the theories and methods of each individual discipline, to establish interdisciplinary links and contradictions, and to consider the possibilities of meta-level integration [9].

Another category, possession of skills, consists of higher level cognitive and communication skills. Cognitive skills of higher level mean such a style of thought, in which a student is able to find the necessary information, analyze and synthesize it, draw logical conclusions, build evidence, critically process facts, properly present the results of the performed study, i.e. it includes different types of thinking: analytical, directed, creative, evaluation, constructive, purposeful. The soft skills of learners also have a direct impact on interdisciplinary thinking in the context of interdisciplinarity of higher education [10].

The eight criteria, which can be divided into two categories, have proved to be relevant for the development of interdisciplinary thinking. The first criterion, soft skills, includes six items. Its three components - intellectual curiosity, respect and openheartedness - point to the necessary positive attitude towards various disciplines, another three patience, studiousness and self-control - relate to the characteristics necessary for the development of cognitive thinking. The second category, previous experience, includes social and educational experience implying, for example, ways of thinking, learning styles and beliefs about the nature of knowledge and learning [11].

The next twelve conditions that make up the learning environment and belong to the four categories are essential for the development of the interdisciplinary approach in learning. The first category - curriculum - is the balance between disciplinarity, interdisciplinarity and discipline knowledge within or beyond the interdisciplinary courses. The second category - teacher - implies five criteria: intellectual community aimed at interdisciplinarity, expert potential of a teacher in interdisciplinarity, consensus on interdisciplinary, team building and team learning [12].

The third category - pedagogical technologies - includes three conditions: pedagogical technologies aimed at interdisciplinarity, pedagogical technologies aimed at active learning and pedagogical technologies aimed at cooperation. It is assumed that these conditions indicate the need to set targets that encourage students to actively apply knowledge rather than simply remember the facts of different disciplines [13]. Besides, such learning tasks should provide students with the opportunity to gain a typical interdisciplinary experience of search and research activities. The fourth category evaluation - includes assessment of students' intellectual status, as well as the assessment of their interdisciplinary status. Both conditions offer assessment tools that include a combined perspective of development and efficiency to help a teacher and students analyze the development of interdisciplinary thinking [14].

The six conditions that make up the learning process have proved to be the most relevant for the interdisciplinarity approach. The first category - the learning model - contains four criteria: gradual, progressive learning, linear learning, 
iterative learning, and progress check. These criteria appear to indicate the need for gradual, linear, phased model coupled with the achievement of intended learning outcomes that serve as benchmarks for each phase in which students are constantly forced to resort to interdisciplinary thinking. The second category - learning activities - includes educational conditions aimed at interdisciplinarity and educational activities aimed at reflection. Both conditions refer to the need for learning activities aimed at acquiring interdisciplinary thinking skills. In particular, creating the situation of contradiction within individual disciplines combined with critical thinking is necessary to encourage students to abandon the concept of absolute knowledge [15]. Publications on the relations between a student, a learning environment, learning conditions, and interdisciplinary thinking do not provide empirical research. However, the criteria presented in the table provide an opportunity to identify hypothetical relations between the identified criteria and the development of interdisciplinary thinking. For example, it can be assumed that student's intellectual curiosity and team learning positively influence the development of interdisciplinary thinking. Besides, gradual progressive advancement appears to be a desirable condition of the learning process, and has a positive impact on interdisciplinary thinking and learning outcomes [16].

\section{CONCLUSION}

In summary, despite the fact that interdisciplinarity in higher education is welcomed and widely practiced nowadays, this issue is not enough studied. The concept of modern engineering education should be based on the principles of individualization, self-development and self-organization, the foundations of which include fundamentality and interdisciplinarity of education.

This paper presents an attempt to analyze this approach in learning to create a platform, which the theory of the interdisciplinarity of higher education can be based on, which will promote further empirical research thus leading to the development of a structure of the interdisciplinary approach in higher education and deepen the understanding of the nature of learning in interdisciplinary thinking.

\section{References}

[1] O. V. Danilova, (2018). "Peculiarities of Forming General Cultural Competences in Students of Institutions of Higher Technical Education by Means of Interdisciplinary Integration," SHS Web of Conferences, vol. 50, p. 01216, April 2018, (CILDIAH-2018, p. 559, 2018)

[2] Zakirova, K., Zakharova-Sarovskaya, M., \& Zakharova, A. (2019). "Creating a successful name (based on psycholinguistic experiments)," SHS Web of Conferences vol. 69, p. 00137 April 2019. (CILDIAH2019, 2019)
[3] Spelt, E. J., Biemans, H. J., Tobi, H., Luning, P. A., \& Mulder, M. (2009). "Teaching and learning in interdisciplinary higher education: A systematic review," Educational Psychology Review,vol. 21 iss. 4, p. $365,2019$.

[4] V. B. Mansilla, E. D. Duraising, "Targeted assessment of students' interdisciplinary work: An empirically grounded framework proposed" The Journal of Higher Education, vol.78 iss. 2, p. 215-237. 2007

[5] A. Y. Polyakov, (2018). "Full-fledged level of physical training of a specialist is an integral part of stability of a work process," SHS Web of Conferences vol. 50, p. 01218 April 2018 (CILDIAH-2018, 2018)

[6] Guseinova, E. E. "Organizational and pedagogical conditions for the development of professional competencies in the technical students' individual work through the example of studying the discipline"Hydraulics and fluid mechanics" European Journal of Contemporary Education, vol. 7 iss. 1, pp. 118-126. 2018

[7] Biggs, J. B. Teaching for quality learning at university: What the student does, McGraw-hill education (UK) 2011.

[8] E. R. Vasilyeva, I. M. Sinagatullin, "Regional and ethnocultural specifics for developing intercultural and lingua-cultural competences: the pedagogical strategy," SHS Web of Conferences vol. 50, p. 01222 April 2018 (CILDIAH-2018, 2018).

[9] K. F. Gabdrakhmanova, G. R.Izmaylova, P. A. Larin "The way of using geothermal resources for generating electric energy in wells at a late stage of operation" IOP Conference Series: Earth and Environmental Science vol. 194, No. 8, p. 1-9. November 2018 (Mining and exploration of mineral resource, 2018)

[10] R.T. Akhmetov, L.S. Kuleshova, and V.V. Mukhametshin, "Absolute Permeability and Distribution of Pore Throats of the Productive Strata of Western Siberia," Atlantis Highlights in Material Sciences and Technology vol. 1, pp. 535-539, June 2019 (ISEES 2019, p. 775, 2019), DOI: 10.2991/isees-19.2019.105.

[11] V.E. Andreev, A.P. Chizhov, Yu.A. Kotenev, Sh.Kh. Sultanov, V.Sh. Mukhametshin, and A.V. Chibisov, "Prediction of Gas Exposure in the Conditions of the Oil Fields of the Volga-Urals," Atlantis Highlights in Material Sciences and Technology vol. 1, pp. 666-669, June 2019 (ISEES 2019, p. 775, 2019),. DOI: 10.2991/isees-19.2019.132.

[12] K T Tyncherov, V Sh Mukhametshin, and L B Khuzina, "Method to control and correct telemetry well information in the basis of residue number system," Journal of Fundamental and Applied Sciences, vol. 9, iss. 2S, pp. 1370-1374, 2017 DOI: 10.4314/jfas.v9i2s.848

[13] R M Shaidullina, A F Amirov, V S Muhametshin and K T Tyncherov, "Designing Economic Socialization System in the Educational Process of Technological University," European Journal of Contemporary Education, vol. 6 (1), pp. 149-158, 2017. DOI: 10.13187/ejced.2017.1.149

[14] Holley, K. A. "Understanding Interdisciplinary Challenges and Opportunities in Higher Education.," ASHE Higher Education Report, vol. 35 iss. 2, pp. 1-131. 2009

[15] Ivanitskaya, L., Clark, D., Montgomery, G., Primeau, R. "Interdisciplinary learning: Process and outcomes," Innovative higher education, vol. 27 iss.2, pp. 95-111. 2002

[16] L.S. Kuleshova and V.V. Mukhametshin, "Estimation of the wells hydrodynamic drag level based on wells geophysical survey data" Atlantis Highlights in Material Sciences and Technology vol. 1, pp. 727-729, June 2019 (ISEES 2019, p. 775, 2019) DOI: 10.2991/isees19.2019.145.

[17] M. A. Lavin, I. Ruebling, , R. Banks, L. Block, M. Counte, G Furman, J. Holt, "Interdisciplinary health professional education: a historical review," Advances in Health Sciences Education, vol. 6 iss. 1, pp. 25-47. 2001 